University of Windsor

Scholarship at UWindsor

\title{
Deep dyslexia and semantic errors: A test of the failure of inhibition hypothesis using a semantic blocking paradigm.
}

Annette Suzanne. Colangelo

University of Windsor

Follow this and additional works at: https://scholar.uwindsor.ca/etd

\section{Recommended Citation}

Colangelo, Annette Suzanne., "Deep dyslexia and semantic errors: A test of the failure of inhibition hypothesis using a semantic blocking paradigm." (2003). Electronic Theses and Dissertations. 1611. https://scholar.uwindsor.ca/etd/1611

This online database contains the full-text of PhD dissertations and Masters' theses of University of Windsor students from 1954 forward. These documents are made available for personal study and research purposes only, in accordance with the Canadian Copyright Act and the Creative Commons license-CC BY-NC-ND (Attribution, Non-Commercial, No Derivative Works). Under this license, works must always be attributed to the copyright holder (original author), cannot be used for any commercial purposes, and may not be altered. Any other use would require the permission of the copyright holder. Students may inquire about withdrawing their dissertation and/or thesis from this database. For additional inquiries, please contact the repository administrator via email (scholarship@uwindsor.ca) or by telephone at 519-253-3000ext. 3208. 
DEEP DYSLEXIA AND SEMANTIC ERRORS: A TEST OF THE FAILURE OF INHIBITION HYPOTHESIS USING A SEMANTIC BLOCKING PARADIGM

by

Annette Colangelo

\author{
A Thesis \\ Submitted to the Faculty of Graduate Studies and Research \\ through Psychology \\ in Partial Fulfillment of the Requirements for \\ the Degree of Master of Arts at the \\ University of Windsor
}

\author{
Windsor, Ontario, Canada \\ 2003 \\ (C) 2003, Annette Colangelo
}




$\begin{array}{ll}\begin{array}{l}\text { National Library } \\ \text { of Canada }\end{array} & \begin{array}{l}\text { Bibliothèque nationale } \\ \text { du Canada }\end{array} \\ \begin{array}{l}\text { Acquisitions and } \\ \text { Bibliographic Services }\end{array} & \begin{array}{l}\text { Acquisisitons et } \\ \text { services bibliographiques }\end{array} \\ \begin{array}{l}\text { 395 Wellington Street } \\ \begin{array}{l}\text { Ottawa ON K1A 0N4 } \\ \text { Canada }\end{array}\end{array} & \begin{array}{l}\text { Ottawa We W K1Angton } \\ \text { Canada }\end{array}\end{array}$

Your file Votre référence ISBN: 0-612-82860-3 Ourfile Notre référence ISBN: 0-612-82860-3

The author has granted a nonexclusive licence allowing the National Library of Canada to reproduce, loan, distribute or sell copies of this thesis in microform, paper or electronic formats.

The author retains ownership of the copyright in this thesis. Neither the thesis nor substantial extracts from it may be printed or otherwise reproduced without the author's permission.
L'auteur a accordé une licence non exclusive permettant à la Bibliothèque nationale du Canada de reproduire, prêter, distribuer ou vendre des copies de cette thèse sous la forme de microfiche/film, de reproduction sur papier ou sur format électronique.

L'auteur conserve la propriété du droit d'auteur qui protège cette thèse. $\mathrm{Ni}$ la thèse ni des extraits substantiels de celle-ci ne doivent être imprimés ou aturement reproduits sans son autorisation. 


\begin{abstract}
Deep dyslexia is an acquired reading disorder in which a previously literate adult produces semantic errors during reading and demonstrates impaired nonword reading. Most models of the syndrome account for the reading errors observed in deep dyslexia in terms of multiple loci of damage. In contrast, Buchanan, McEwen, Westbury, and Libben (2003) proposed that reading errors result from damage in the phonological output lexicon alone. According to this formulation, semantic errors evolve from impaired explicit assess and production due to failure of inhibition. In contrast, implicit processing is assumed to be intact in deep dyslexia. The current investigation tests several predictions that evolve from the failure of inhibition hypothesis using a semantic blocking paradigm for explicit and implicit tasks. The results of the semantic blocking paradigm support the distinction between implicit and explicit processing and provide evidence for failure of inhibition as an explanation for semantic errors in deep dyslexia.
\end{abstract}


To Tony with love and gratitude 


\section{ACKNOWLEDGEMENTS}

I would like to thank JO for her participation and continued interest in our research program over the years. It was my early work with her as a research assistant that first sparked my interest in neuropsychology and helped define the direction of my graduate studies. Her commitment to the development of a better understanding of language deficits is unparalleled. I admire her strength and fortitude in facing the challenges of communication in the context of linguistic difficulties and her unrelenting motivation to contribute her talents in new ways.

I am grateful to the numerous people who helped make this research project possible. Thank you Chris Westbury for your assistance with the stimulus set and for helping to coordinate data collection. Without your continued support, this research project would not have gone so smoothly. Also, thank you for your helpful comments on an earlier draft of this thesis.

I am indebted to my advisor, Lori Buchanan. Thank you for cultivating potential and for nurturing ideas to fruition. Most of all, thank you for your genuine enthusiasm for research and your commitment to new knowledge; it is infectious. Your efforts with respect to my research and dedication to graduate students in general are simply tireless. I was never left floundering. Thank you for all your encouragement and humour. Because of you, working on this thesis was enjoyable!

Thank you to my committee members, Richard Caron and Kathryn Lafreniere. I appreciate how generous you were with your time. Thank you for your willingness to explore new domains of research and your commitment to improving the quality of my work. Your comments were well appreciated and contributed greatly to the completion of this thesis.

I am eternally grateful for the support and understanding of my family. Thank you for your patience and guidance. Your willingness to listen provided me the opportunity to organize my ideas out loud. Your thoughtful questions encouraged a better understanding of the theoretical underpinning of my research and stimulated novel research directions. Thank you for picking up where I left off and for providing me balance, especially when I felt overwhelmed. 


\section{TABLE OF CONTENTS}

ABSTRACT iii

DEDICATION iv

ACKNOWLEDGEMENTS V v

LIST OF TABLES vii

LIST OF FIGURES viii

CHAPTER

I. INTRODUCTION 1

The Symptom-complex of Deep Dyslexia 2

Accounts for Deep Dyslexia 3

II. THE SELECTION IMPAIRMENT HYPOTHESIS 10

Implicit and Explicit Access $\quad 10$

Implicit and Explicit Access: Phonology 11

Explicit Access: Failure of Inhibition 13

Failure of Inhibition: Number of Semantic Neighbourhoods 15

Failure of Inhibition: Neighbourhood Size 19

Implicit Access Despite Impaired Explicit Access: Phonology 20

Dissociation between Implicit Versus Explicit Semantic Access 21

Summary $\quad 25$

Predictions $\quad 26$

III. PATIENT DESCRIPTION 28

IV. METHODS 29

Lexical Decision Task $\quad 29$

Word Reading Task $\quad 30$

V. RESULTS 31

Lexical Decision Task $\quad 31$

Word Reading Task $\quad 36$

VI. DISCUSSION 40

VII. CONCLUSIONS

VIII. LIMITATIONS 46

IX. FUTURE DIRECTIONS 48

REFERENCES

APPENDIX 1:Items from the LD and Naming Tasks 56

VITA AUCTORIS $\quad 58$ 


\section{LIST OF TABLES}

TABLE 1: Mean RT and Accuracy for Correct Words and Nonwords with Associated t-values ............................................................32

TABLE 2. Averaged RTs for Word Responses in the Initial and Corrected Data Set...................................................................................33

TABLE 3. Interaction for Group versus Position..................................36

TABLE 4. Reading Responses to Words in Blocked and Random Conditions.......38 


\section{LIST OF FIGURES}

FIGURE 1. An adapted version of the dual route model............................5

FIGURE 2. MANOVA for Significant Interaction.................................36

FIGURE 3. Errors in Reading for Blocked and Random Conditions.................38 


\section{INTRODUCTION}

Reading is a complex skill that depends on the ability to process the whole word by extracting meaning from its printed representation, as well as the ability to sound out words based on rules for spelling-to-sound correspondences. Acquired brain damage can selectively impair these components of reading ability. Most reading disorders that result from brain damage are broadly classified into three categories: surface dyslexia, phonological dyslexia, and deep dyslexia.

Patients with surface dyslexia are able to sound out letter strings based on rules for spelling-to-sound correspondences but are unable to access whole word representations from print (Marshall \& Newcombe, 1973). Consequently, aloud reading for regular words (i.e., words with common spelling-to-sound correspondences, such as gave, save, and cave) and nonwords (i.e., nonsense letter strings that can be decoded based on rules for spelling-to-sound correspondences, such as frip) is intact. However, surface dyslexics read exception words incorrectly because these words have irregular spelling-to-sound correspondences (e.g., have). Instead, they regularize exception words by applying the rules for typical pronunciations. For example, surface dyslexics pronounce the word have such that it rhymes with gave, save, and cave (Buchanan, Hildebrandt, \& MacKinnon, 1999).

In phonological dyslexia, patients are able to access the meaning of whole word representations from print, but are unable to assemble sound segments that correspond to word spellings (Beauvois \& Derouesne, 1978). As such, phonological dyslexics are able to read familiar words, including regular and exception words. However, these patients are unable to successfully read aloud nonwords (Buchanan et al., 1999). 
Deep dyslexic patients are similar to phonological dyslexics insofar as both patient groups are unable to successfully read aloud nonwords. However, deep dyslexic patients also demonstrate impaired whole word reading (Marshall \& Newcombe, 1973). Impaired reading for words include visual errors, derivational errors, as well as semantic errors. Given that these patients evidence multiple reading impairments, deep dyslexics are assumed to have a form of reading disorder that is central to the reading system (Buchanan et al., 1999). This thesis focuses on the syndrome of deep dyslexia with a particular emphasis on the production of semantic errors during aloud reading.

\section{The Symptom-Complex of Deep Dyslexia}

Deep dyslexia is an acquired reading disorder in a previously literate adult. Given the relative homogeneity of reading deficits in most patients with deep dyslexia, the disorder is considered a syndrome (Coltheart, 1980a). The defining symptom of deep dyslexia is the production of semantic errors during aloud reading. Semantic errors are defined as incorrect naming responses that relate to the target in meaning (e.g., tide $\rightarrow$ water). Although semantic errors are the hallmark symptom, deep dyslexics also produce other types of reading errors. For example, visual errors occur when the response resembles the target in terms of shared letters (e.g., gallant $\rightarrow$ gallon and perform $\rightarrow$ perfume). In addition, some errors reflect substitutions of one function word for another in the same class (e.g., for $\rightarrow$ and), termed function-word substitutions. Derivational errors result when the target and response differ only in terms of bound morphemes (e.g., sick $\rightarrow$ sickness) $)^{1}$. These types of errors co-occur with semantic errors frequently and are

\footnotetext{
${ }^{1}$ A morpheme is the smallest unit containing linguistic meaning (e.g., -ed, cat, -ness, baby, un-, etc.). Morphology is the description of the word form in terms of morphemes (Reisberg, 1997). Although important for a comprehensive understanding of linguistic processing in deep dyslexia, a further discussion of morphology is beyond the scope of this paper.
} 
therefore considered part of the symptom-complex (see Coltheart, 1980a for a comprehensive discussion of error types and the symptom-complex in deep dyslexia).

In addition to types of errors produced, deep dyslexia is defined by an inability to read aloud nonsense letter strings, called nonwords. Typically, these patients also demonstrate effects for concreteness (better reading of high-imageability, e.g., cat, than low-imageability words, e.g., happy), syntactic category (better reading of nouns than adjectives, which are easier to read than verbs), and word class (better reading of content, e.g., nouns, than function words, e.g., for, the, etc.) during oral reading (Coltheart, 1980a).

\section{Accounts for Deep Dyslexia}

Several models have been proposed to account for deep dyslexic reading performance. Although these accounts are different on many levels, Buchanan et al. (1999) emphasize the common assumption that deep dyslexic patients are unable to process subword phonology (i.e., they are unable to assemble sound segments corresponding to the spelling of letter strings) (e.g., Glosser and Friedman, 1990; Morton and Patterson, 1980; Plaut and Shallice, 1993; Coltheart, 1980b). Although conceptualized differently depending on the model, each account assumes reading is a multi-step process: The processing of words involves visual analysis of the printed word, which eventuates access to representations in the orthographic lexicon (i.e., the 'mental dictionary' that contains spelling descriptions for words in the reading vocabulary, known as orthography). Subsequently, orthographic information feeds into the semantic system (i.e., a system for representing word meanings) to access the meaning of words. Semantic representations then access the phonological lexicon (i.e., the 'mental dictionary' that contains sound specifications for words, known as phonology) where the eventual 
selection of a particular entry supports an oral response. Within this framework for lexical processing, access can be understood as the point at which entries associated with presented information are activated (Buchanan, Colangelo, \& Van Orden, 2002).

The following section presents a brief review of models for deep dyslexia with an emphasis on the manner in which these frameworks conceptualize the occurrence of semantic errors and the inability to read aloud nonwords (see Buchanan et al., 1999 for a systematic review of these models in terms of the inability to process subword phonology).

\section{The Dual Route Account: The Morton and Patterson Model}

In general, the dual-route account (e.g., Morton \& Patterson, 1980) postulates that normal reading occurs by either of two possible routes: the assembled and addressed routines (see Figure 1). The assembled route (pathway A) uses rules regarding the relationship between letters and sounds to sequence sound segments (i.e., phonemes) in order to evolve a pronunciation. Because regular words (e.g., save and wave) reflect these rules, the assembled route can produce their correct pronunciations. However, exception words (e.g., pint) have atypical spelling-to-sound correspondences and therefore violate these rules. Consequently, processing of exception words via the assembled route does not yield correct pronunciations. Notably, this route cannot process words by directly accessing its meaning in the semantic system. However, it can read nonwords that reflect typical spelling-to-sound correspondences.

The addressed route (pathway B) relies on previous experience with letter strings, which evolves the formation of whole-word representations in the orthographic lexicon. Providing that the system has encountered the printed word before, its orthographic representation is activated. Once the orthographic representation is activated, it accesses 
the corresponding meaning in the semantic system. The semantic representation then proceeds to the phonological output lexicon, which supports the production of an oral response (i.e., the aloud reading response). Because exception words are represented in the orthographic lexicon (i.e., the system has previously encountered them), they can be processed via the addressed reading route. Thus, although the addressed reading route cannot process nonwords, it can process words associated with semantic information.

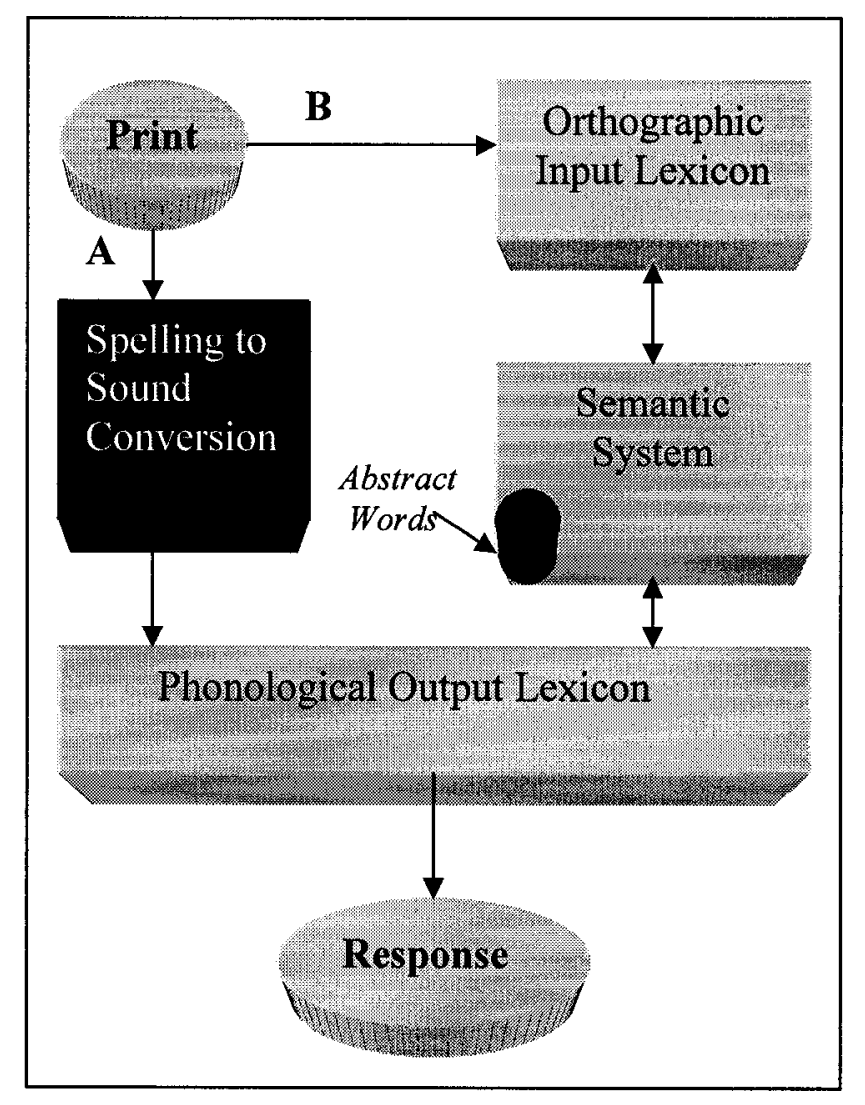

FIGURE 1. An adapted version of the dual route model (Buchanan et al., 1999). The darkened modules indicate locations of damage in deep dyslexia

In order to account for both the occurrence of semantic errors and the inability to read aloud nonwords, Morton and Patterson (1980) postulated that deep dyslexia reflects multiple loci of damage within the dual-route model for reading. To explain the inability to read aloud nonwords, this model proposes that the assembled route is unavailable in 
deep dyslexia. As a consequence, deep dyslexics are assumed to lack the capacity to assemble phonology. Instead, reading is assumed to proceed through the semantically mediated addressed route. Normally, the addressed route is capable of supporting normal reading through whole word access. However, based on the fact that deep dyslexics produce semantic errors during reading, damage to this route is also assumed.

\section{The Continuum Account: Phonological and Deep Dyslexia}

Glosser and Friedman (1990) proposed that deep dyslexia and phonological dyslexia represent endpoints along the same continuum of reading disability (also see Laine, Niemi, \& Marttila, 1990; Sartori, Barry, \& Job, 1984). This conceptualization is based on reports of patients with deficits that were initially consistent with a diagnosis of deep dyslexia, but that evolved over time to a pattern of impairment associated with phonological dyslexia (e.g., see Glosser \& Friedman, 1990; Klein, Behrmann, and Doctor, 1994; Southwood \& Chatterjee, 2001).

In general, both the dual-route and analogy accounts of deep dyslexia assume that semantic errors reflect damage to the semantic system, whereas impaired nonwordreading results from damage to the nonsemantic reading route (Buchanan et al., 1999). However, Glosser and Friedman $(1990,1996)$ argued for an analogy model in which reading via the nonsemantic route is accomplished by mapping subword orthographic information directly to phonological entries in the output lexicon (i.e., no rules for spelling-to-sound correspondences). According to this account, evolution from deep to phonological dyslexia reflects recovery of the semantic system and, thus, the disappearance of semantic errors during reading (but see Friedman, 1996 for other analogical aetiologies of recovery). However, nonword reading is still impaired because damage to the direct orthography-to-phonology route does not recover. 


\section{The Connectionist Account: Computational Modeling}

The connectionist approach to deep dyslexia is based on a computational model of normal reading implemented as nodes interconnected in a parallel distributed processing network (Plaut, 1999). The nodes that comprise the network form layers that represent various features of a word. At each layer, similar words are represented as similar patterns of activity. The orthographic layer represents a word in the form of a pattern of activation across individual orthographic nodes. For oral reading to proceed, the orthographic pattern of activation representing a word produces the pattern of activation that corresponds to that word across nodes at the semantic level. In networks that include a layer for phonology, the pattern of semantic information activated by orthographic input activates the pattern of nodes representing the phonology of the word.

Plaut and Shallice (1993) produced many deficits analogous to those observed in deep dyslexia by introducing a single lesion to a connectionist network that mapped orthography to phonology via semantics. However, Buchanan et al. (1999) noted that Plaut and Shallice used connectionist networks that mapped semantic activation directly onto the phonological layer. Given that nonwords have no semantic representation, these networks could not support nonword reading. Buchanan et al. (1999) stated that, to the extent that nonword reading was impossible, the architectures were already dyslexic prior to lesioning. As such, the inability to support nonword reading can "...be likened to a second source of damage in the model... (p. 198)."

\section{The Right Hemisphere Hypothesis: The Neurological Account}

The Right Hemisphere Hypothesis proposes that the deficits in deep dyslexia reflect the contributions of the right hemisphere to reading after the dominant left hemisphere has been damaged (Coltheart, 1980b). This view assumes that damage to the 
left-hemisphere eliminates access to the left orthographic lexicon. In order for reading to proceed, orthographic access to a right-hemisphere lexicon is necessary. However, the right hemisphere cannot subserve the production of language. Therefore, once the orthographic lexicon accesses the semantic representation, it is transmitted from the right to the left hemisphere. This information is then used to access a phonological entry in the left-hemisphere lexicon where a pronunciation is selected and subsequently produced (Coltheart, 1980b; Coltheart, 2000).

The Right-Hemisphere Hypothesis stipulates that how semantic errors evolve depends on the type of error. Specifically, semantic errors can either share features with the target (e.g., dog and cat share many features, including the fact that both have fourlegs, are furry, have a tail, etc.) or are associatively related to the target (associative semantic errors do not share features with the target but are related because they co-occur in language, e.g., next $\rightarrow$ exit and merry $\rightarrow$ Christmas). Shared-feature semantic errors are assumed to result because a "degree of disparity" is accepted between the semantic representation that is transmitted from the right hemisphere and the lexical entry in the left-hemisphere that is selected for response. In contrast, associative semantic errors are assumed to evolve from the associative network of the right hemisphere wherein associated entries are spuriously activated when the target is presented. Errors result from incorrect selection from among activated candidates and the subsequent transmission of that semantic representation to the left hemisphere for production (Coltheart, 1980b; Coltheart, 2000).

According to Buchanan et al. (1999), the major strength of the Right Hemisphere Hypothesis is that it postulates neurologically plausible substrates for linguistic processing. However, the account does not specify the mechanism for the occurrence of 
semantic errors and is therefore difficult to evaluate at a theoretical level. In addition, this model assumes that the right hemisphere is completely unable to derive phonology from print. Given the assumption that the right hemisphere mediates the processing of orthographic information in the context of left hemisphere damage, this explanation for deep dyslexia posits an inability to read nonwords (Buchanan et al., 1999). 


\section{THE SELECTION IMPAIRMENT HYPOTHESIS}

Although formulated differently, Buchanan et al. (1999) emphasize that each of the aforementioned models of deep dyslexia assume multiple loci of damage in the reading system that evolves impaired phonology (given impaired ability to read aloud nonwords) and impaired semantics (given errors in reading, including semantic errors). In contrast, Buchanan, Hildebrandt, and MacKinnon $(1994,1999)$ proposed that selection impairment in the phonological output lexicon alone accounted for the various types of reading errors observed in deep dyslexia. Recently, Buchanan, McEwen, Westbury, and Libben (2003) further specified the selection impairment hypothesis. According to this formulation, production errors evolve from the failure of inhibition.

\section{Implicit and Explicit Access}

Given the conceptualization of word production as a multi-step process, lexical processing can potentially be compromised at different theoretical levels. Buchanan et al. (2003) introduced a framework for studying word production deficits in neurolinguistic patients, called PEIR. This model acknowledges the distinction between word representations and access to those representations. Within the PEIR formulation, word production depends on explicit access, which depends on implicit access, which in turn depends on intact representations. At each level, semantics, phonology, and morphology comprise components of representation and processing that are separate yet interact with one another.

Within the PEIR framework, Buchanan et al. (2003) proposed that production errors (e.g., reading) reflect compromised explicit access. Explicit access refers to "overt knowledge regarding relevant semantic, morphological, or phonological characteristics of words" (e.g., able to judge correctly that horse is more related in meaning to saddle than 
house)(Buchanan et al., 2002). In contrast, because the representation itself is assumed to be intact, implicit access is preserved. Implicit access is conceptualized in terms of sensitivity to phonological, morphological, or semantic manipulations without requiring explicit access or production. For example, implicit access can be indexed in terms of faster responses in lexical decision ${ }^{2}$ to table when it is preceded by chare than a regular nonword, even in the context of not being able to overtly decide which of chare and chaig sound like real English words (Buchanan et al., 2002). Lexical decision is considered an implicit task because although individuals decide the lexical status of letter strings (e.g., word or nonword), lexical access is indexed in terms of facilitation as measured by faster response times for one condition relative to the other.

\section{Implicit and Explicit Access: Phonology}

Several recent findings provide support for the proposed dissociation between implicit and explicit access to phonological representations, as well as challenge conceptualizations of deep dyslexia that hinge on complete inability to process phonology. Katz and Lanzoni (1992) reported a deep dyslexic patient who showed a normal advantage for rhyming words (e.g., bribe-tribe) relative to trials with nonrhyming stimuli (e.g., couch-touch) in a lexical decision task. Hildebrandt and Sokol (1993) similarly established that implicit phonological knowledge contributes to word recognition performance in deep dyslexia: Their patient evidenced a normal regularity effect for low-frequency words such that he made faster and more accurate lexical decisions to words with typical spelling-sound correspondences (e.g., gave, save) than to words with atypical spelling sound correspondences (e.g., have). These investigations

\footnotetext{
${ }^{2}$ The lexical decision task requires that individuals decide as quickly as possible while maintaining accuracy whether a letter string is a word or a nonword.
} 
indicate that, although deep dyslexic patients evidence impaired ability to explicitly assemble phonology (i.e., read aloud nonwords), these patients are influenced by word phonology at an implicit level.

Notably, Buchanan, Hildebrandt, and MacKinnon (1994, 1996) demonstrated that some patients with deep dyslexia evidence preserved implicit phonological processing for nonwords. In a series of experiments with three deep dyslexic patients, they found a normal pseudohomophone effect: Reaction times to reject nonwords that sound like words (e.g., taybul) were slower than responses to orthographic control nonwords (e.g., tarbul). In addition, these patients showed normal semantic priming with pseudohomophone primes in lexical decision (e.g., faster reaction times to the word chair when preceded by the prime taybul than after orthographic control nonwords e.g., tarbul). Cumulatively, these results indicate that deep dyslexics are sensitive to implicit phonological information for words and nonwords despite impaired explicit access. Importantly, implicit phonological analysis resulted in normal effects ${ }^{3}$, which suggests intact phonological representations and normal patterns of activation. In addition, the findings for intact implicit phonological processing of nonwords indicate that the primary locus of the deficit in deep dyslexia is not sublexical (i.e., deep dyslexic patients have preserved assembled phonology). Buchanan et al. (2003) proposed that the phonological deficits observed in deep dyslexia reflect production errors due to compromised explicit access. According to this perspective, compromised explicit access results from selection impairments in the phonological output lexicon due to a failure of inhibition.

\footnotetext{
${ }^{3}$ Normal effects refer to an observed pattern of performance that is typical of college-aged participants.
} 


\section{Explicit Access: Failure of Inhibition}

The selection impairment view articulated in terms of failure of inhibition proposes intact processing via addressed and assembled reading routes, as well as normal activation in the semantic system. In normal nonword naming, the assembled phonology of the nonword enters the phonological output lexicon, which activates the phonological neighbours of these nonwords (i.e., phonological neighbourhood can be defined as those words that share all but one phoneme with the target ${ }^{4}$ ). By method of analogical mapping, the assembled phonology of the nonword is checked against the phonological candidates of activated neighbours. Given that there is no lexical entry in the phonological output system for the nonword, this process results in a "nonmatch." Consequently, the assembled phonology represents the "best guess" of the system (Buchanan et al., 1999).

According to the failure of inhibition hypothesis, an inability to name nonwords in deep dyslexia results from a failure to perform an efficient lexical check in the phonological output system. Nonword naming in deep dyslexia is impaired by the random pattern of activation that evolves from a failure to inhibit spuriously activated candidates in the phonological output system. Random activation eventuates inefficient analogical mapping. As such, the time required to check activated lexical candidates often exceeds the time that the assembled pronunciation can be maintained in memory. As a result, no response can be made. Although the system generally "times out" before activated candidates are mapped to the assembled phonology, the word that has received the most activation (i.e., a close neighbour) may occasionally be chosen. On these trials, a word is offered in response to the nonword (Buchanan et al., 1999).

${ }^{4}$ Buchanan \& Westbury (2000) 
Within this conceptualization, when a real word is presented in print, the orthographic representation for that word is activated in the orthographic lexicon, which in turn activates the representation associated with that word in the semantic system. Through a network of interconnections, activation from the target representation spreads to other representations within its neighbourhood of semantically related entries. For example, the neighbourhood for cat defined in terms of semantics might include $d o g$, mouse, cheese, scratch, etc. The neighbourhood of semantically related entries is then activated in the phonological output lexicon. Errors occur because all associated candidate representations (i.e., the neighbourhood) are activated in the phonological lexicon but are not pruned through inhibition, as would normally be the case in an intact system. Therefore, reduced inhibitory connections result in decreased sensitivity to the activation levels of neighbours and impaired explicit access. This reduced inhibition increases the likelihood that neighbours are incorrectly selected for response.

With respect to semantic neighbourhood, the failure of inhibition hypothesis predicts that any manipulation that decreases the number of options for selection in the phonological output lexicon should decrease the number of semantic errors. Alternatively, the error rate is expected to increase in conditions that cause more candidates to be activated. According to this formulation, phonemic cues (i.e., the first phoneme of the word) should improve deep dyslexic performance during reading because they boost the activation level of candidates with corresponding phonology and thereby constrain the potential candidates for selection. In contrast, providing phonological miscues associated with semantically related candidates should function to decrease performance during reading. Consistent with this hypothesis, supplying the initial phoneme of target words in oral reading has been shown to have strong facilitatory effects on performance with deep 
dyslexic patients (Katz \& Lanzoni, 1997; Buchanan, Kiss, Burgess, 2000), whereas miscuing resulted in poorer performance (Katz \& Lanzoni, 1997).

\section{Failure of Inhibition: Number of Semantic Neighbourhoods}

Given the postulation that deep dyslexics are sensitive to the number of potential candidates available for selection, a prediction that evolves from the failure of inhibition hypothesis is that the number of semantic neighbourhoods associated with each word should impact reading performance (Buchanan et al., 2003). Specifically, if reading errors result from a failure to inhibit spuriously activated candidates within a target's semantic neighbourhood, then increasing the number of semantic neighbourhoods that are associated with a particular word should function to increase semantic errors because there is a corresponding increase in the number of candidates that are available for selection. Important to the test of this prediction is the fact that compound words can be associated with three separate meanings (e.g., the compound word as a whole entity, as well as each of its two constituents), which indicates that these stimuli are potentially linked to three separate semantic neighbourhoods (e.g., one neighbourhood associated with the compound word DEADLINE, a separate neighbourhood associated with the word $\mathrm{DEAD}$, and yet another neighbourhood associated with the word LINE). In order to vary the number of semantic neighbourhoods associated with each compound word, Buchanan et al. (2003) manipulated the transparency/opacity of compound constituents in a reading task with a deep dyslexic patient (JO). For transparent constituents, the meaning of the compound word entity can be predicted on the basis of the meaning of its constituents. In contrast, opaque constituents have no obvious semantic relationship to the compound word. Buchanan et al. (2003) conceptualized compound transparency/opacity as category membership in a four-cell transparency scheme: transparent-transparent 
(TT)(e.g., DOORMAN), opaque-transparent (OT)(e.g., POTHOLE), transparent-opaque (TO)(e.g., SHOEHORN), and opaque-opaque (OO)(e.g., DEADLINE).

Importantly, the transparency/opacity manipulation varied the number of neighbourhoods associated with each compound word. For example, TT compound words are associated with only one semantic neighbourhood because both of the constituents reside in the same neighbourhood as the compound word (i.e., BED and ROOM are both semantic associates of the word BEDROOM and are therefore in the same neighbourhood). Compound words that contain one transparent and one opaque constituent (OT and TO compound words) are associated with two semantic neighbourhoods: One neighbourhood that contains the compound word and the transparent constituent, as well as a completely separate neighbourhood for the opaque constituent, given that this constituent is not semantically related to the compound word entity (e.g., for the compound word BUTTERFLY, there is one semantic neighbourhood for FLY and BUTTERFLY and one distinct neighbourhood for BUTTER). Fully opaque compounds are associated with three distinct neighbourhoods such that there is one neighbourhood for the compound word (e.g., HUMBUG) and one completely separate semantic neighbourhood for each of its opaque constituents (e.g., neither HUM nor BUG are semantic associates of the compound word HUMBUG).

Given that there is different number of neighbourhoods associated with each of the four types of compound words, the failure of inhibition hypothesis predicts that these words differ with respect to explicit lexical access (Buchanan et al., 2003). Specifically, because there is only one semantic neighbourhood associated with TT compound words, only candidates associated with that neighbourhood are activated for potential response selection. Although errors are still expected due to failure of inhibition, Buchanan et al. 
(2003) predicted that these words would be the easiest to explicitly access. In contrast, OO compound words were expected to be the most difficult to access explicitly because these compound words $(\mathrm{OO})$ are associated with three distinct semantic neighbourhoods and a correspondingly large number of activated candidates competing for selection in the context of failure of inhibition. With respect to OT and TO compound words, both types of compound words are associated with two semantic neighbourhoods. However, the fact that English compound words are right-headed ${ }^{5}$ indicates that OT compound words should be accessed with more facility than TO compound words. Therefore, Buchanan et al. (2003) predicted that accuracy would be highest for TT compound words, followed by OT compound words, followed by TO compound words, and finally OO compound words. In addition to accuracy rate, the transparency/opacity manipulation was predicted to affect semantic errors in a specific direction: A higher number of semantic errors were expected for opaque compound words relative to transparent compound words, given the increased number of semantic neighbourhoods and associated activated candidates. Furthermore, given that they expected opaque constituents to be accessed as separate representations from its whole word entity, Buchanan et al. (2003) predicted that errors would reflect the different parts of the word such that semantic errors would occur in response to both the opaque constituent and compound word entity.

Buchanan et al., (2003) argued that the results of the transparency/opaque manipulations showed implicit analysis of the semantic information from whole word compounds despite impaired ability to read these words aloud (as first responses, JO was

\footnotetext{
${ }^{5}$ Right-headed refers to the fact that the features of the whole compound word most frequently reflect the features of the right-handed constituent in terms of syntactic category and meaning (e.g., BLACKBOARD $\rightarrow$ is a BOARD, but is not necessarily BLACK; BULLFROG $\rightarrow$ is a FROG not a BULL) (Buchanan et al., 2002).
} 
only able to read 10 of the 94 items correctly). Implicit access to words was evident in the fact that JO read transparent compound words more accurately than opaque compound words (e.g., of the 10 compound words initially read aloud correctly as their whole word entities, 9 were TT). When all words that were eventually read correctly were considered, reading performance was in the predicted direction: fully transparent compounds $(40 \%$ correct), opaque-transparent compound words ( $33 \%$ correct), transparent-opaque compound words ( $23 \%$ correct), and opaque-opaque ( $13 \%$ correct). Given that transparency is determined only in relation to the meaning of the constituents with respect to the compound word, Buchanan et al. (2003) argued that better performance for transparent than opaque manipulations indicates implicit semantic processing of the entire word, even if she was unable to successfully read it aloud. Importantly, for those compounds that contained an opaque constituent, JO frequently responded with semantic errors to the whole compound word entity, as well as to its opaque constituents. According to Buchanan et al. (2003), this finding indicates intact implicit access to both the compound word and its constituents, not just to the constituents in isolation. These results not only provide support for predictions that evolve from the failure of inhibition hypothesis, but also highlight the distinction between implicit and explicit semantic processing: Although failure of inhibition may compromise production or explicit access, JO demonstrated preserved implicit access to semantic information (Buchanan et al., 2003).

Based on their findings, Buchanan et al. (2003) suggested that semantic information is available to patients with deep dyslexia to an extent greater than is evident in oral reading performance. In addition, the degree to which this information was explicitly accessible depended on manipulations that varied the number of potential 
candidates activated for selection. Important to the test of the failure of inhibition hypothesis is that it evolves predictions that are contrary to performances observed in the neurologically intact population. With respect to the transparency/opacity manipulation, reading order reflected placement of the transparent constituent: JO read the first place constituent first the majority of the time for TT $(85 \%), \mathrm{OO}(83 \%)$, and TO $(85 \%)$ words. However, she read the second word first for more than half $(56 \%)$ of the OT stimuli. Buchanan et al. (2003) noted that this latter finding is in contrast to strong reading order preference in normals that proceeds from left to right.

\section{Failure of Inhibition: Neighbourhood Size}

Departure from normal performance based on predictions of the failure of inhibition hypothesis has also been found in deep dyslexia for neighbourhood size. Neighbourhood size ${ }^{6}$ can be defined in terms of orthography (i.e., the number of real words that result from replacing one letter in the target word), phonology (i.e., the number of words that result from replacing one phoneme in the target word), or semantics (i.e., the number of words that co-occur with the target in similar contexts in text - see the computational model of semantics explained in Buchanan, Burgess, Lund, 1996). Through the spread of activation, words with larger neighbourhoods activate a correspondingly larger number of potential candidates for selection than words with smaller neighbourhood size. In the context of failure of inhibition, a greater number of potential candidates for selection (both phonological and semantic) are predicted to increase the likelihood of reading errors. Indeed, Buchanan et al. (1996) showed that deep dyslexics made more errors during reading as the size of the semantic neighbourhood

\footnotetext{
${ }^{6}$ See Buchanan \& Westbury (2000) for specific definitions of orthographic and phonological neighbourhood size.
} 
increased. In addition, Buchanan, Kiss, and Burgess (2000) found effects for both phonological and semantic neighbourhood size: The number of reading errors increased as a function of increased neighbourhood size. The effect for poorer reading performance as a function of semantic and phonological neighbourhood size in deep dyslexia is in contradistinction to the strong facilitatory effects of these variables in word recognition tasks with normal participants (Buchanan, Westbury, \& Burgess, 2001).

Notably, failure of inhibition effects are only expected when the task requires that a particular candidate in the phonological output lexicon be selected for response: Impaired performance results from a reduced ability to distinguish the target from its competitors due to a failure to inhibit candidates that were spuriously activated through the spread of activation. Given a reduced ability to distinguish the target from its competitors, an increase in reading errors is expected. However, if the task does not require the selection of a particular candidate in the phonological output lexicon, but merely access to implicit information regarding the target, performance should not reflect failure of inhibition effects. In fact, on tasks that require only implicit processing, lexical manipulations should impact performance in a manner consistent with that observed in the normal population.

\section{Implicit Access Despite Impaired Explicit Access: Phonology}

To date, evidence for normal effects on tasks that require implicit processing in the context of impaired explicit access have been found in deep dyslexia for phonological manipulations: Katz and Lanzoni (1992) reported a normal advantage for rhyming words (e.g., bribe-tribe) relative to trials with nonrhyming stimuli (e.g., couch-touch) in a lexical decision task. In addition, Hildebrandt and Sokol (1993) found a normal regularity effect for low-frequency words (decreased RTs in LD to words such as gave and save compared 
with have). With respect to nonword phonology, Buchanan, Hildebrandt, and MacKinnon $(1994,1996)$ demonstrated a significant pseudohomophone effect (increased RTs in LD to taybul than tarbul), as well as semantic priming with pseudohomophone primes in lexical decision (e.g., decreased RTs to chair after taybul than after tarbul). These findings not only suggest dissociation in performance in deep dyslexia based on task demands for implicit versus explicit processing, but also indicate that deep dyslexics have normal sensitivity to phonological information when only implicit access is required.

If deep dyslexic patients demonstrate dissociation in performance with respect to implicit and explicit lexical access for phonological information, then dissociation in performance based on semantic information should also manifest. Specifically, not only should there be evidence that deep dyslexics process semantic information on an implicit level, as was suggested by poorer performance due to number of semantic neighbourhoods (Buchanan et al., 2003), but also that performance based on implicit access proceeds in a normal fashion i.e., deep dyslexics should show normal semantic effects.

\section{Dissociation between Implicit Versus Explicit Semantic Access}

The finding for normal semantic effects based on implicit processes in the context of impaired explicit performance and production (e.g., reading errors) would support the theoretical distinction between implicit and explicit access for semantic information in deep dyslexia. However, this result in isolation would not necessarily implicate failure of inhibition as the mechanism of impaired explicit access and production. In order to indicate failure of inhibition as the mechanism for impaired explicit access and production, performance must be shown to vary based on manipulations assumed to 
impact the effects of inhibition. In this regard, evidence for a double dissociation ${ }^{7}$ in performance based on implicit and explicit task demands given the same experimental manipulation would not only provide support for the distinction between implicit and explicit semantic access, but also lend support to the failure of inhibition hypothesis as the mechanism for failed explicit access and production. Because its effects have been widely studied in the normal population, semantic priming is a potentially rich domain in which to seek such a double dissociation.

Reports of semantic priming in word recognition studies with normal participants are ubiquitous in cognitive psychology (e.g., McKoon \& Ratcliff, 1992; McNamara, 1992a, 1992b, 1994). Semantic priming results when response times to items (e.g., butter) are faster and more accurate when they are presented after semantically related words (e.g., bread) than after unrelated words (e.g., nurse). Semantic priming effects have been found in a variety of tasks, including lexical decision (e.g., Meyer \& Schvaneveldt, 1971) and semantic categorization (e.g., Rips, Shoben, \& Smith, 1973). Explanations for semantic priming generally hinge on the assumption of spread of activation to related entries in the semantic system. By increasing the activation levels of semantically related items prior to presentation, the spread of activation facilitates lexical access to subsequent items.

Importantly, several studies have investigated the influence of multiple related primes in lexical decision tasks. For example, Schmidt (1976) used one, three, or eight prime conditions that were either semantically related or unrelated to the target word.

\footnotetext{
${ }^{7}$ Double dissociation refers to a pattern of performance in which a patient is found to have a deficit on task A, but not task B (single dissociation). However, given the same experimental manipulation with a different task, the patient demonstrates impaired performance in the opposite direction: a deficit on task B, but not task A.
} 
Results revealed a larger priming effect for eight primes compared with the one prime condition. Klein, Briand, Smith and Smith-Lamothe (1988) compared single prime conditions that were identical (e.g., fruit/fruit or pear/pear) with double prime conditions in which the primes were different (e.g., fruit/pear or pear/fruit) in lexical decision. Primes were related, unrelated, or neutral to the target. Results indicated larger priming effects in double prime conditions than single prime conditions. Brodeur and Lupker (1994) reported similar results in lexical decision tasks that examined the effect of a single category prime compared with four categorically related primes. The authors found that four primes provided a larger advantage than a single prime. Balota and Paul (1996) also investigated multiple primes in lexical decision. The conditions included primes that converged in meaning onto the same semantic representation (e.g., lion-stripes-tiger) or diverged onto different semantic representations (e.g., kidney-piano-organ). Facilitation evidenced for both convergent and divergent primes. Notably, priming effects with twoprime convergent and divergent manipulations were also observed for naming tasks. More recently, Damian, Vigliocco, and Levelt (2001) showed faster naming for targets in the context of six semantically related words than unrelated items. Cumulatively, these results indicate that semantic context facilitates performance for normal participants in both implicit (lexical decision) and explicit (naming) tasks.

In order to support the assumption for intact implicit access to semantic representations in deep dyslexia, as the failure of inhibition hypothesis postulates, performance on tasks without a selection requirement should reflect performance observed in normal participants. In other words, deep dyslexics should produce normal effects in conditions with implicit task demands because failure of inhibition does not impact the availability of lexical information, only explicit retrieval and subsequent 
production. Given that the normal effect for semantic context is facilitation, the failure of inhibition hypothesis predicts semantic priming in lexical decision for words blocked into semantically related categories relative to random conditions: As each word is presented in succession, the corresponding entry in the semantic system is activated and this activation spreads to semantically related items. As more words are presented within the semantic category, more semantically related candidates are activated through the spread of activation. Boosting the activation level of semantically related items prior to their presentation should facilitate responses to these items because lexical status is easier to determine. In addition, because more semantically related items are activated for each presentation within a given semantic category, faster and more accurate response times are expected to accrue for items presented in the second half of each semantic category relative to items in the first half.

Strong support for the failure of inhibition as the mechanism for impaired explicit access and production in deep dyslexia would include evidence for a double dissociation in performance based on implicit and explicit task demands, given the same experimental manipulation. In contrast to the facilitative effects of semantic context on naming observed in normals, the failure of inhibition hypothesis predicts poorer reading performance for deep dyslexics on tasks that present words grouped into semantically related categories compared with random order presentations: As each word is presented in succession, the corresponding entry in the semantic system is activated. Through the spread of activation, semantically related entries are spuriously activated and that activation spreads to the phonological output lexicon. As more words are presented within the semantic category, more semantically related candidates are activated. In the context of slowed or reduced inhibitory connections, the number of options for selection 
in the phonological output lexicon continue to increase with each semantically related presentation, thereby increasing the probability of semantic errors relative to conditions that present words in random order. In addition to absolute number of semantic errors, reading errors should accrue in a pattern consistent with what is expected based on increased options available in the phonological output lexicon. Specifically, given that options for selection continue to increase in the phonological output lexicon with each semantically related presentation, more errors are predicted for words presented in the second half of each semantic category than the first half. Preliminary support for these hypotheses comes from a study investigating picture naming with a deep dyslexic patient: Wilshire and McCarthy (2002) found that performance deteriorated when the targets were semantically blocked on a task that required the repeated naming of a small set of pictures. The authors concluded, "the experimental manipulations appeared to increase the competition posed by other recently produced items from within the target set (p. 173)." Thus, semantic context is predicted to compromise performance in conditions with explicit processing demands in deep dyslexic patients.

\section{Summary}

To review, lexical decision requires only that participants respond to the lexical status of an item i.e., explicit selection is not required and thus there are no effects for failure of inhibition. In the case of lexical decision, the spread of activation increases the activation levels of subsequent items prior to their presentation. Increasing the level of activation of an item prior to presentation makes its lexical status easier to determine and therefore facilitates performance. In addition, because more semantically related items are activated for each presentation within a given semantic category, increased facilitation is 
expected for items presented in the second half of each semantic category relative to items in the first half.

In contrast, in conditions that necessitate a selection requirement (e.g., naming), increasing the number of activated candidates in the phonological output lexicon by blocking stimuli in semantically related categories is predicted to increase competition in the context of slowed or reduced inhibitory connections. As a result, more semantic errors are expected. In addition, errors should accrue in a pattern consistent with increased options in the phonological output lexicon: Given that options for selection continue to increase in the phonological output lexicon with each semantically related presentation, more errors are predicted for words presented in the second half of each semantic category than the first half.

Evidence for a double dissociation in performance based on implicit and explicit task demands would provide support for the distinction between implicit and explicit semantic access. Moreover, this finding would lend support to the failure of inhibition hypothesis as the mechanism for failed explicit access and production.

\section{Predictions}

I proposed to test the following predictions that evolve from the failure of inhibition hypothesis:

1. A patient with deep dyslexia should produce faster and more accurate reaction times in lexical decision to words blocked into semantically related categories compared with random conditions.

2. Given that more semantically related items are activated for each presentation within a particular semantic category, response times in lexical decision are 
predicted to be faster and more accurate for items presented in the second half relative to items in the first half of each semantic category.

3. Semantic errors are expected to increase when a patient with deep dyslexia is asked to read words blocked according to semantic category relative to unblocked presentations.

4. A semantic interference effect is predicted for blocked conditions: More errors are expected in reading responses to words in the second half of each semantically related category than for items in the first half. 


\section{PATIENT DESCRIPTION}

$\mathrm{JO}$ is a 51-year old woman with 14 years of formal education, two of which were at the postsecondary level. She was first tested 20 years after the removal of a tumour in the left temporal-parietal region, which left JO with right side paralysis and profound language disturbances. During the initial screening phase conducted in 1999, JO was asked to read aloud 300 single-syllable words and 108 nonwords. McEwen, Westbury, Buchanan, and Libben (2001) reported the following summary of her responses: JO read only 109 of the 300-monomorphemic English words correctly. Of 191 errors, 32 were frank semantic errors (e.g., debt $\rightarrow$ money). Responses to targets also included phonological (e.g., style $\rightarrow$ smile), orthographic (e.g., tried $\rightarrow$ tired), and morphological (e.g., shown $\rightarrow$ showing) errors. With respect to nonword reading, JO initially failed to produce even a single correct response. Her pattern of errors on these tasks is consistent with the profile of deep dyslexia. 


\section{METHODS}

\section{Lexical Decision Task}

The stimulus set consisted of 300 common monosyllabic and multisyllabic words blocked according to 20 semantic categories. The categories were selected based on list stimuli used by Roediger and McDermott (1995). These lists were initially constructed by obtaining the first 15 semantic associates listed in Russel and Jenkin's (1954) word association norms. Thus, fifteen semantically related words comprise each of the 20 categories (see Appendix 1.). These stimuli have been widely used to study the impact of context on memory and have been shown to produce strong semantic effects.

In the blocked condition, the words were presented in semantically related categories interleaved with 300 nonwords. In the unblocked condition, the same words were presented in random order with the nonword stimuli. Conditions were counterbalanced and temporally separated such that the blocked and random conditions were presented twice, each presentation on different days. For both presentations of blocked (blocked 1 and blocked 2) and random (random 1 and random 2) conditions, the items were presented in the identical order: Both presentations in the blocked conditions presented each word in semantically related categories in the order that they originally appeared on the lists. Similarly, both presentations of random conditions were presented in the same fixed randomized order. For each lexical decision trial, a 250-millisecond fixation cross preceded the target. Each target was presented individually on a computer screen using DirectRT software (Jarvis, 2002). The target remained on the screen until a lexical decision was registered. To indicate her responses, JO was asked to press a key designated for word or nonword responses. JO was instructed to respond quickly without 
compromising accuracy. RTs were measured in milliseconds from the onset of the letter string to key press.

\section{Word Reading Task}

The identical 300 monosyllabic and multisyllabic words were presented as targets in a naming task. In the blocked condition, the words were presented together in 20 semantically related categories. Each word was individually printed in 16-point font on $3 \mathrm{X} 5$ index cards. JO was asked to read each word aloud and her responses were recorded verbatim. The task was participant paced and no time limits were imposed. Two weeks later, JO was asked to read the same 300 words presented in random order. Qualitative analysis was performed on her aloud responses to determine the number and type of reading errors (e.g., semantic, phonological, morphological errors, as well as circumlocutions and no responses). 


\section{RESULTS}

The two independent variables in both the lexical decision and reading tasks were Group versus Position. The dependent variables in the lexical decision task were accuracy and response time. The dependent variable of interest in the reading task was error rate. Group refers to the manipulation that presented words in semantically related categories compared with random presentations, whereas Position refers to the comparison of responses in first versus second half conditions. Reference to Group and Position conditions occurs throughout the discussion of the results.

\section{Lexical Decision Task}

Analysis of accuracy revealed no differences between blocked and random conditions in lexical decision, $\chi^{2}(3, \underline{\mathrm{N}}=1200)=0.66, \underline{p}=0.88$. However, responses to word trials yielded higher accuracy rates than responses to nonword trials $(p<.0001$, see Table 1). In addition, mean RTs were faster for correct responses to words than correct responses to nonwords across Group conditions $(\mathrm{p}<.0001$, see Table 1.). These results replicate the standard finding for faster and more accurate RTs for words than nonwords and suggest intact ability to access lexical status in deep dyslexia. Refer to Table 1 for a summary of mean RTs before they were corrected (conditions 1-and 2-blocked and 1-and 2-random were subsequently collapsed and average RTs calculated, as well as only data in which responses were correct in both conditions were considered in further analysis in order to create stable means). These data will not be considered further. 
TABLE 1. Mean RT and Accuracy for Correct Words and Nonwords with Associated t-values

\begin{tabular}{|l|r|r|r|r|}
\multicolumn{1}{c}{} & \multicolumn{3}{c}{ Blocked } & \multicolumn{3}{c}{ Random } \\
\cline { 2 - 6 } \multicolumn{1}{c}{ Trial 1 } & \multicolumn{1}{c}{ Trial 2 } & \multicolumn{1}{c}{ Trial 1 } & \multicolumn{1}{c}{ Trial 2 } \\
\hline Mean RT Words & 1428 & 1480 & 1509 & 1440 \\
Mean RT NWs & 1711 & 1642 & 1794 & 1653 \\
\hline Nonword - Word RTs (t-value) & -8.48 & -4.52 & -4.57 & -5.75 \\
degrees of freedom & 550 & 559 & 548 & 558 \\
\hline$\%$ Acc Words & 0.98 & 0.99 & 0.97 & 0.98 \\
\% Acc NWs & 0.86 & 0.88 & 0.87 & 0.88 \\
\hline Chi-square for accuracy, $\chi^{2}(1, \underline{N}=600)$ & 26.18 & 26.35 & 19.64 & 24.11 \\
p-value & $<.0001$ & $<.0001$ & $<.0001$ & $<.0001$ \\
\hline
\end{tabular}

According to the failure of inhibition hypothesis, facilitatory effects in lexical decision are expected for words blocked into semantically related categories relative to conditions that present the same words randomly. To determine whether blocked conditions produced priming compared with random order presentations, counterbalanced conditions (1-and 2-blocked; 1-and 2-random) were collapsed: The mean RTs of the first (1-blocked) and second (2-blocked) presentation of each item in blocked conditions were calculated in order to derive the Average RT for each word. The Average RT for each item was then calculated for paired words across 1-and 2-random conditions. Only data from trials on which JO responded correctly to both the first and second presentation of words in semantically related groups were included in the analysis for 1-and 2-blocked conditions. Likewise, only data from correct trials for both the first and second presentation of words were included in the analysis for 1-and 2-random order conditions. Consequently, 8 of the 300-paired words were removed from the blocked condition and 12 of the 300-paired words were removed from the random condition. Analysis of mean RT for Averaged items revealed no difference between blocked $(\underline{\mathrm{M}}=1448, \underline{\mathrm{SD}}=307)$ 
and random conditions $(\underline{\mathrm{M}}=1471, \underline{\mathrm{SD}}=405), \underline{\mathrm{t}}(578)=-0.79, \underline{\mathrm{p}}=0.43$ (see Table 2 for Averaged RTs). In addition, no difference manifested between Group conditions when only trials to which JO responded correctly for both blocked $(\underline{\mathrm{M}}=1445, \underline{\mathrm{SD}}=305)$ and random $(\underline{\mathrm{M}}=1468, \underline{\mathrm{SD}}=406)$ presentations were considered $\underline{\mathrm{t}}(566)=-0.75, \underline{\mathrm{p}}=0.45$ (see Table 2 for these corrected values). Thus, the general expectation for faster and more accurate reaction times in lexical decision to words blocked into semantically related categories compared with random conditions did not manifest.

TABLE 2. Averaged RTs for Word Responses in the Initial and Corrected Data Set

\section{LD Response Times (in Milliseconds) for Averaged and Corrected Trials}

\section{Condition}

\section{Blocked}

Averaged RTs Corrected RTs
Random

Averaged RTs Corrected RTs

\begin{tabular}{lrrrr}
\hline Mean RT & 1448 & 1445 & 1471 & 1468 \\
SD & 307 & 305 & 405 & 406
\end{tabular}

On a more specific level, the failure of inhibition hypothesis predicts faster and more accurate lexical decisions for items presented in the second half of each semantic category relative to items in the first half. This prediction is based on the assumption that facilitation occurs as more semantically related items are activated for successive presentations within a particular semantic category. Initial analysis of error rate indicated that the expectation for improved accuracy for the second half of words in semantically related categories relative to words presented in the first half of categories did not eventuate secondary to the fact that JO rarely made errors in her responses to words, regardless of the condition (approximately $97 \%$ accurate in the first half of trial-1 blocked and $99 \%$ accurate in the first half of trial-2 blocked, compared with $98 \%$ accurate in the second half of trial- 1 blocked and $98 \%$ accurate in the second half of trial- 2 blocked, $\chi^{2}$ 
$(3, \underline{\mathrm{N}}=560)=1.16, \underline{\mathrm{p}}=0.76 ;$ approximately $97 \%$ accurate in the first half of trial-1 random and $99 \%$ accurate in the first half of trial- 2 random, compared with $96 \%$ accurate in the second half of trial-2 random and $97 \%$ accurate in the second half of trial-2 random $\left.\chi^{2}(3, \underline{N}=560)=2.25, \underline{p}=0.52\right)$. Given comparable error rates across conditions, accuracy will not be considered beyond this point.

To test the prediction for faster response time, each of the semantically related groups in the 1-and 2-blocked conditions were divided into first and second half items. The first and second half items were defined in relation to their position on the original category lists. For example, one list of associates included butter, food, eat, sandwich, rye, jam, milk, flour, jelly, dough, crust, slice, wine loaf, and toast. The blocked lexical decision condition presented these same words interleaved with nonwords. Thus, first half items for the blocked LD condition included the words butter, food, eat, sandwich, rye, jam, milk. The second half items in the blocked LD condition included jelly, dough, crust, slice, wine, loaf, and toast. Given that 15 words comprised each semantically related group, the median $\left(8^{\text {th }}\right)$ item (e.g., flour) was deleted from all of the 20 categories that comprised the 1-and 2-blocked conditions. This deletion resulted in equal number items in first half ( 7 items) and second half ( 7 items) conditions. To collapse the first and second presentation of words in the 1-and 2-blocked conditions, the Averaged RT for each item was calculated. Given that the unblocked condition presented list words in random order with nonwords and words from all other semantically related lists, each item in the first and second half random condition (Averaged RT for first and second presentation of 1-and 2-random conditions) was matched to the corresponding item in the blocked condition. If any response in the word pairs were incorrect, either within the 1and 2-blocked and 1-and 2-random conditions, or between these conditions, the word was 
entirely discarded from the analysis. Thus, 7 of the 140-paired words were removed from the first half condition and 8 of the 140-paired words were removed from the second half condition. The remaining stimuli were comprised of identical items in the first half of blocked and random conditions and identical items for the second half of blocked and random conditions.

The mixed ANOVA (Group within and Position between) was performed on corrected Averaged RTs. The analysis revealed no main effect for either Group $(F(1,263)$ $=0.02, \underline{p}=0.89)$ or Position $(F(1,263)=0.74, \underline{p}=0.39)$. However, there was a significant interaction between Group and Position $(F(1,263)=6.16, \underline{p}<.0137)$. Planned comparisons of that interaction showed that the RTs in the second half of the blocked condition were faster than RTs in the first half $(\mathrm{p}=.058)$. The second half of the blocked condition was also faster than the second half of the random condition $(\mathrm{p}<.02)$. None of the other contrasts approached significance (first half random compared with second half random, $\underline{p}=0.11$; first half blocked compared with first half random, $\mathfrak{p}=0.25$; first half random compared with second half blocked, $p=0.45$; first half blocked compared with second half random, $\underline{p}=0.64$ ). See Table 3 and Figure 2 for a summary of these findings. Taken together, the findings for faster RTs for the first half compared with the second half of the blocked condition, as well as the difference between the second half of blocked relative to random conditions, are consistent with an interpretation that hinges on the facilitatory effects of spread of activation on lexical decisions. 
TABLE 3. Interaction for Group versus Position

\begin{tabular}{|c|c|c|c|}
\hline $\begin{array}{l}\text { 1st Blocked } \\
(\underline{M}=1487)\end{array}$ & $\begin{array}{l}\text { 1st Random } \\
(M=1446)\end{array}$ & $\begin{array}{l}\text { 2nd Blocked } \\
(M=1420)\end{array}$ & $\begin{array}{l}\text { 2nd Random } \\
(M=1504)\end{array}$ \\
\hline $\begin{array}{l}\text { 1st Blocked } \\
\text { 1st Random } \\
\end{array}$ & $\underline{p}=0.25$ & $\begin{array}{l}\text { 1st Random } \\
\text { 2nd Blocked }\end{array}$ & $\underline{p}=0.45$ \\
\hline $\begin{array}{l}\text { 1st Blocked } \\
\text { 2nd Blocked }\end{array}$ & $p=0.06$ & $\begin{array}{l}\text { 1st Random } \\
\text { 2nd Random }\end{array}$ & $\underline{p}=0.11$ \\
\hline $\begin{array}{l}\text { 1st Blocked } \\
\text { 2nd Random }\end{array}$ & $\mathrm{p}=0.64$ & $\begin{array}{l}\text { 2nd Blocked } \\
\text { 2nd Random }\end{array}$ & $p=0.02$ \\
\hline
\end{tabular}

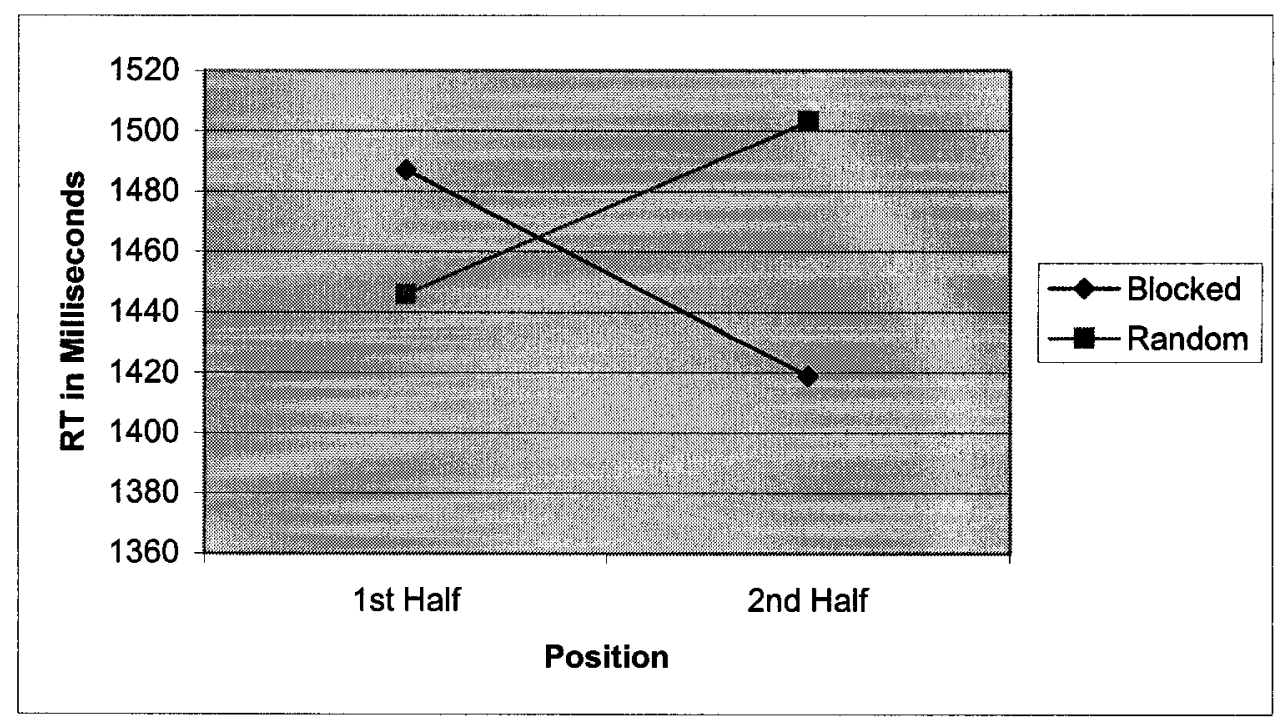

FIGURE 2. MANOVA for Significant Interaction

\section{Word Reading Task}

In addition to semantically related responses, JO produced phonological, morphological, and orthographical errors, as well as short circumlocutions and no responses. This pattern of errors is consistent with her typical performance and with the 
classic deep dyslexia profile. As first responses, JO made a total of 158 errors to words in the blocked condition and 128 errors to words presented randomly, $\chi^{2}(1, \underline{N}=600)=6.01$, $\underline{p}=0.01$. Importantly, the number of nonsemantic errors remained relatively constant across conditions (111 errors in the blocked condition and 121 errors in the random condition; $\left.\chi^{2}(1, \underline{\mathrm{N}}=600)=0.7, \underline{p}=0.40\right)$.

According to the failure of inhibition hypothesis, deep dyslexics are predicted to produce more semantic errors in blocked conditions than when words are presented randomly. In the current investigation, the Group manipulation revealed striking support for this prediction: JO made 47 semantic errors as first responses to targets in the blocked condition. In contrast, she produced only 7 semantic errors in response to the same words presented in random order $\chi^{2}(1, \underline{\mathrm{N}}=600)=32.56, \underline{\mathrm{p}}<0.001$ (refer to Table 4 for examples). This finding is in contrast to the facilitative effect of semantic context on naming performance observed for the normal population (Schmidt, 1976; Klein et al., 1988; Brodeur \& Lupker, 1994; Balota \& Paul, 1996; Damian et al., 2001) and lends support for the failure of inhibition hypothesis.

Similar to the lexical decision task, the first and second half items in the Position comparison were defined in relation to their position in the semantic categories (e.g., butter, food, eat, sandwich, rye, jam, and milk were in the first half of the category, whereas jelly, dough, crust, slice, wine, loaf, and toast were in the second half of the category). The finding for a semantic interference effect provides additional support for the failure of inhibition hypothesis (Figure 3.): JO produced more errors in the second half of each list compared with the first half. In fact, the proportion of overall errors increased from $47 \%$ (66/140) of responses to the first half of words across lists to $59 \%$ $(83 / 140)$ of responses for the second half of the words, $\chi^{2}(1, \underline{N}=280)=4.15, \underline{p}<0.05$. In 
contrast, the difference in number of errors in the first half and second half of the semantic category for matched words in the random condition did not approach significance, $\chi^{2}(1, \underline{\mathrm{N}}=280)=0.93, \underline{p}=0.33$.

TABLE 4. Reading Responses to Words in Blocked and Random Conditions

\begin{tabular}{|c|c|c|}
\hline Target & $\begin{array}{c}\text { Response to Target in Blocked } \\
\text { Presentation }\end{array}$ & $\begin{array}{c}\text { Response to Target in Random } \\
\text { Presentation }\end{array}$ \\
\hline butter & & \\
\hline food & & eating \\
\hline eat & & \\
\hline sandwich & & \\
\hline rye & & \\
\hline jam & & \\
\hline milk & sugar, flour & \\
\hline flour & jam, jelly & \\
\hline jelly & & \\
\hline dough & crumbs & \\
\hline crust & cheese & \\
\hline slice & & \\
\hline wine & loaves & \\
\hline loaf & & \\
\hline toast & & \\
\hline
\end{tabular}

*Blank cells indicate correct responses

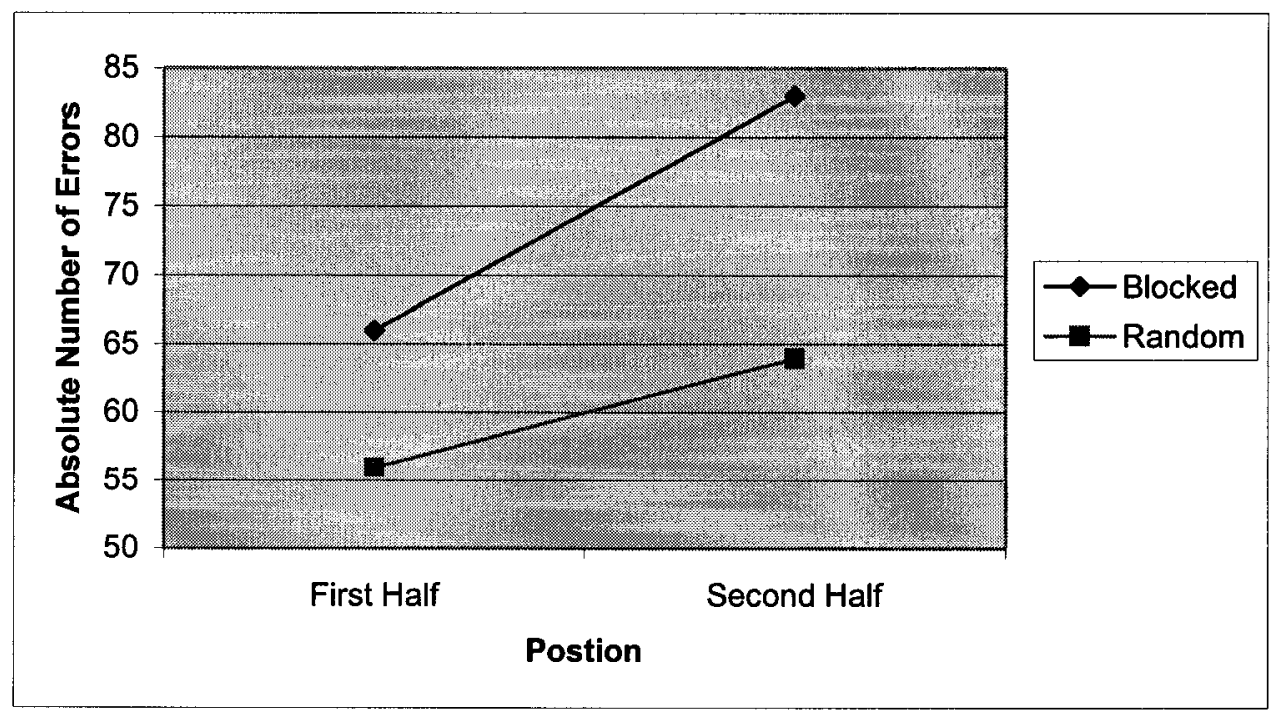

Figure 3. Errors in Reading for Blocked and Random Conditions 
Together, these results are consistent with the prediction of poorer reading performance as more words within each semantic category are presented. Given spurious activation of semantically related candidates in the context of slowed or reduced inhibitory connections, the number of options for selection in the phonological output lexicon increases with each semantically related presentation. 


\section{DISCUSSION}

The failure of inhibition hypothesis posits a theoretical distinction between implicit and explicit access in deep dyslexia (Buchanan et al., 2003). Specifically, this view argues that reading errors are due to impaired explicit access and production due to failure of inhibition in the phonological output lexicon. Notably, the effects of failure of inhibition are assumed only in conditions that have an explicit selection requirement. In contrast, the failure of inhibition hypothesis proposes that implicit access to semantic information is intact in deep dyslexia. Evidence for intact implicit access requires that performance in deep dyslexic parallels that observed in neurologically intact participants on tasks based on implicit processes. In other words, deep dyslexics should produce normal effects in conditions with implicit task demands because failure of inhibition does not impact the availability of lexical information, only explicit retrieval and subsequent production. The current investigation examined the distinction between implicit and explicit processes in deep dyslexia using semantic blocking in lexical decision and naming as a test for the failure of inhibition hypothesis.

Research with normal participants has repeatedly shown robust effects for semantic priming under implicit and explicit conditions (see McKoon \& Ratcliff, 1992; McNamara, 1992a, 1992b, 1994; also see Damian et al., 2002 for naming). Given that the normal effect for semantic context is facilitation, the failure of inhibition hypothesis predicted that deep dyslexics would evidence improved performance in lexical decision (i.e., an implicit task) for words blocked into semantically related categories relative to random conditions: As each word is presented in succession, the corresponding entry in the semantic system is activated and this activation spreads to semantically related items. As more words are presented within the semantic category, more semantically related 
candidates are activated through the spread of activation. Boosting the activation level of semantically related items prior to their presentation facilitates responses to these items because lexical status is easier to determine. In addition, because more semantically related items are activated the further one reads within a given semantic category, faster response times were expected to accrue for items presented in the second half of each semantic category relative to items in the first half.

Although a difference did not occur between blocked and random conditions overall, results of the study provide support for normal semantic effects based on implicit processes in deep dyslexia. Specifically, responses in blocked lexical decision were faster to words presented in the second half of semantic categories relative to words presented in the first half of categories. This result indicates that additional semantic information facilitates performance such that stronger effects of semantic priming evolve the further within a category that words were presented. Notably, there were faster responses in the blocked condition to words in the second half of semantic categories than responses to these same words presented randomly. Given that the random presentation of category words eliminates any possible effect for order within categories, the difference between second half category items in blocked and random conditions strongly implicates semantic priming.

The results for semantic priming in blocked lexical decision provide support for intact implicit access in deep dyslexia and suggest dissociation in performance based on implicit and explicit task demands. However, normal semantic effects based on implicit processes in isolation does not necessarily implicate failure of inhibition as the mechanism of impaired explicit access and production. In order to indicate failure of inhibition as the mechanism for impaired explicit access and production, performance 
must be shown to vary based on manipulations assumed to impact the effects of inhibition. The presentation of semantically related words in blocked and random conditions during reading provides the context in which to test failure of inhibition. In contrast to the facilitative effects of semantic context on lexical decision, the failure of inhibition hypothesis predicted poorer reading performance for deep dyslexics on tasks that present words grouped into semantically related categories compared with random order presentations: Through the spread of activation, semantically associated entries are activated in the semantic system and this activation spreads to the phonological output lexicon. As each word in the category is presented in succession, more semantically related candidates become activated. In the context of slowed or reduced inhibitory connections, spuriously activated entries are not suppressed and the number of options for selection continues to increase in the phonological output lexicon. As such, each semantically related presentation increases the probability of semantic errors relative to conditions that present words in random order. Given that options for selection continue to increase in the phonological output lexicon with each semantically related presentation, more errors were predicted for words presented in the second half of each semantic category than the first half.

The results of semantic blocking on reading performance provided striking support for the failure of inhibition hypothesis. Specifically, presenting words together in semantic categories substantially increased the number of semantic errors relative to the condition that presented these same words randomly. Notably, the increase in semantic errors for blocked conditions implies intact ability to activate semantically related candidates, thus suggesting normal spread of activation. As such, performance cannot easily be attributed to a failure to access entries in the semantic system. Instead, the 
increase of semantic errors for blocked conditions indicates a deficit in the ability to address semantically related entries in the phonological output system: As more candidates become excited through the spread of activation in the semantic system more options become available for selection in the phonological output lexicon and there is a corresponding increase in the probability that a semantically related candidate is selected for response. Thus, slowed or reduced inhibitory connections in the phonological output system can account for increased errors in semantically blocked conditions.

In addition to the difference in semantic errors in blocked relative to random conditions, presenting words together in semantic categories produced a significant semantic interference effect: The number of errors increased for second half items relative to words in the first half of categories. Notably, there was no difference between first and second half category items when these words were presented randomly. These findings indicate a disadvantage for words presented in the second half of blocked categories and are consistent with an interpretation that hinges on the impact of semantic context and the failure of inhibition. Importantly, the findings for increased semantic errors in blocked relative to random conditions and more errors in second half category items than first half items for the blocked condition is in contrast to the facilitative effect of semantic context on naming performance observed for the normal population (Damian et al., 2001). 


\section{CONCLUSIONS}

The results of the semantic blocking paradigm with lexical decision and naming tasks provide evidence for a double dissociation in deep dyslexic performance based on implicit and explicit task demands. Given that lexical decision only requires response to the lexical status of an item (i.e., no explicit selection requirement), performance on this task is not impaired by failure of inhibition in deep dyslexia. Instead, presenting semantically related items together in blocks results in spread of activation that increases the activation levels of subsequent items prior to their presentation. Increasing the level of activation of an item prior to presentation makes its lexical status easier to determine and therefore facilitates performance. Because more semantically related items are activated for each presentation within a given semantic category, facilitation increases the further within the category that items are presented. Indeed, the results of lexical decision revealed semantic priming for words in the second half of semantic categories relative to items in first half categories. Notably, these results are consistent with the effects for semantic context observed in neurologically intact participants (Schmidt, 1976, Klein et al., 1988, Brodeur \& Lupker, 1994, Balota \& Paul, 1996, Damian et al., 2001). As such, the findings suggest that implicit processing of semantic information is intact in deep dyslexia.

Given the postulation for impaired explicit access and production in deep dyslexia, conditions that block semantically related words together increase the number of activated candidates in the phonological output lexicon. More activated candidates cause increased competition in the context of slowed or reduced inhibitory connections and thereby increase the likelihood that a semantically related incorrect candidate is selected for response. The finding for significantly increased semantic errors for words presented 
in semantic blocked conditions relative to random presentations provide striking support for this account of reading errors in deep dyslexia. In addition, errors accrued in a pattern consistent with increased options in the phonological output lexicon: Given that options for selection continue to increase in the phonological output lexicon with each semantically related presentation, more errors occurred for words presented in the second half of each semantic category than the first half. Importantly, these results are consistent with an interpretation that hinges on failure of inhibition as the mechanism for impaired explicit access and production. Taken together, these results indicate the power of the semantic blocking paradigm as a test for the failure of inhibition hypothesis. 


\section{LIMITATIONS}

Although the results of the semantic blocking paradigm provide strong support for predictions that evolve from the failure of inhibition hypothesis, several improvements to the design of the study would have likely increased the power of the semantic blocking paradigm to test the failure of inhibition hypothesis. The most notable improvement is related to the stimuli used for semantic blocking. The category lists were selected based on stimuli used by Roediger and McDermott (1995). These lists were initially constructed by obtaining the first 15 semantic associates listed in Russel and Jenkin's (1954) word association norms. Given that the lists were originally constructed to study false memory effects, the words in each category are less associated with each other than they are to a critical, nonpresented item (i.e., the word that all list items of semantic associates were originally generated from). Categories comprised of words that are strongly associated to one another and thus very likely to reside within the same instead of overlapping semantic neighbourhood -- such as would be expected for synonyms-- would have possibly been more appropriate.

Another improvement to the design of the study is in regards to the first and second half comparisons in the lexical decision task. First and second half of category items in the blocked condition were always presented in the identical order: Both presentations in the random conditions were presented in the same fixed randomized order. Similarly, both presentations of blocked conditions presented each word in semantically related categories in the order that they originally appeared on the reading lists. Instead, a design that balanced first and second half category items such that items in the first half were switched to positions in the second half and vice versa, would have increased the statistical power of the analysis from a between and within mixed item 
design to within item comparisons with the same degrees of freedom. These improvements to the design, as well as several extensions of the blocking paradigm, are planned for future research directions. 


\section{FUTURE DIRECTIONS}

The findings of the current investigation suggest several extensions of the blocking paradigm to test the failure of inhibition hypothesis. According to the failure of inhibition hypothesis, visual analysis of the printed word eventually activates its representation in the semantic system during reading. Through the spread of activation, the semantic neighbourhood associated with the target is also activated (i.e., semantically related entries). This activation feeds into the phonological output lexicon to activate the sound specifications of entries within the target's semantic neighbourhood. Each sound specification is associated with its own phonological neighbourhood (i.e., words that share phonemes). Once these sound specifications are activated in the phonological output lexicon, associated phonological neighbourhoods are then activated. In the context of failure of inhibition, none of these entries are subsequently pruned. Thus, both the semantic neighbourhood, as well as the phonological neighbourhoods associated with sound specifications of words within the semantic neighbourhood, remain available for possible response selection.

Notably, Buchanan, Kiss, and Burgess (2000) found effects for both phonological and semantic neighbourhood size during reading in deep dyslexia such that the number of reading errors increased as a function of increased neighbourhood size. These findings are consistent with the failure of inhibition hypothesis, which predicts increased reading errors as the number of activated candidates in the phonological output lexicon increases. Importantly, poorer reading performance as a function of semantic and phonological neighbourhood size in deep dyslexia is in contrast to the strong facilitatory effects of these variables in word recognition tasks with normal participants (Buchanan, Westbury, \& Burgess, 2001). 
In the current study, blocking words according to semantically related categories increased the number of semantic errors during reading relative to random order presentations because, according to the failure of inhibition hypothesis, the manipulation increased the number of spuriously activated candidates in the phonological output lexicon. Performance was shown to dissociate on a task based on implicit processing demands such that semantic priming occurred. Given that semantic priming represents the normal effect, this finding indicates intact implicit processing in deep dyslexia. By extension then, if deep dyslexia is due to a deficit in the ability to explicitly address candidates in the phonological output lexicon, words blocked according to initial phoneme should also impact reading in a predicted direction: Phonological blocking should function to increase the number of phonological errors relative to random presentations during aloud reading. However, because failure of inhibition is not expected to impact performance on implicit tasks, performance should be facilitated given these same words presented in blocks during lexical decision (i.e., normal performance is facilitated by additional phonological information).

Blocked paradigms have also been employed in research on false memories in neurologically intact populations. Investigations of false memory typically present lists of study words (e.g., bed, rest, awake, tired) that converge in meaning on a critical nonpresented word (e.g., sleep), which reliably increases the likelihood that the nonpresented critical item will be falsely remembered at test (Roediger \& McDermott, 1995). A spread of semantic activation is thought to mediate the false memory effect. More specifically, blocked presentations are assumed to increase the saliency of semantic relationships among list words relative to random presentations (Toglia, Neuschatz, \& Goodwin, 1999). Although memory performance for previously studied items generally 
improves dramatically with increased semantic processing (for reviews see Craik and Lockhart, 1972; Lockhart and Craik, 1990), it also increases the probability that nonpresented critical items will be spuriously activated and subsequently selected for response on memory trials: Toglia et al., (1999) found increased recall accuracy at the expense of a higher intrusion rate for theme-consistent nonpresented critical items when target items were presented in a blocked, as opposed to random format (also see Mather, Henkel, \& Johnson, 1997). These findings have implications for research with deep dyslexia.

Based on the results of the semantic blocking paradigm in the current investigation, when wordlists are presented via print and deep dyslexics are asked to read the lists for study, they should produce more semantic errors in the blocked relative to the random condition. Deep dyslexic patients should also be more vulnerable to the false recognition effect when target items are presented in a blocked format than the random condition (i.e., the normal effect). In addition, given the increased probability that nonpresented critical items were activated and not suppressed in the context of failure of inhibition for blocked relative to random conditions, encoding of spuriously activated nonpresented critical items during learning is predicted to be greater for deep dyslexics compared with normals. Thus, the false memory effect for deep dyslexic patients should significantly exceed that which is observed for neurologically intact participants. In contrast, correct identification of previously studies items should be facilitated in a manner comparable with normals because of the opportunity available for increased semantic processing in blocked conditions. 


\section{REFERENCES}

Balota, D.A. \& Paul, S.T. (1996). Summation of activation: Evidence from multiple primes that converge and diverge within semantic memory. Experimental Psychology: Learning, Memory, and Cognition, 22, 827-845.

Brodeur, D.A. \& Lupker, S.J. (1994). Investigating the effects of multiple primes: An analysis of theoretical mechanisms. Psychological Research, 57, 1-14.

Beauvois, M.F., \& Derouesne, J. (1979) Phonological alexia: Three dissociations. Journal of Neurology, Neurosurgery, and Psychiatry, 42, 1115-1124.

Buchanan, L., Burgess, C., \& Lund, K. (1996a). Overcrowding in semantic neighbourhoods: A computational analysis of deep dyslexia. Brain and Cognition, 32, $111-114$.

Buchanan, L., Hildebrandt, N., \& MacKinnon, G.E. (1994). Implicit phonological processing in deep dyslexia: A rowse is implicitly a rose. Journal of Neurolinguistics, 8 , $163-182$.

Buchanan, L., Hildebrandt, N., \& MacKinnon, G.E. (1996). Phonological processing of nonwords in deep dyslexia: Typical and independent. Journal of Neurolinguistics, 9, 113-133.

Buchanan, L., Hildebrandt, N., \& MacKinnon, G.E. (1999). Phonological processing in acquired deep dyslexia re-examined. In R. Klein, \& P. McMullen (Eds). Converging methods for understanding reading and dyslexia. Cambridge, MA, US: The Mit Press.

Buchanan, L., Kiss, I., \& Burgess, C. (2000). Phonological and semantic information in word and nonword reading in a deep dyslexic patient. Brain \& Cognition, $\underline{43}, 65-68$. 
Buchanan, L., McEwen, S., Westbury, C., \& Libben, G. (2003). Semantic and semantic error: Implicit access to semantic information from words and nonwords in deep dyslexia. Brain \& Language. Special Issue: Meaning in language, 84, 65-83.

Buchanan, L. \& Westbury, C (2000). Wordmine database: Probabilistic values for all four to seven letter words in the English Language. http://www.wordmine.org

Buchanan, L., Westbury, C., \& Burgess, C. (2001). Characterizing semantic space: Neighborhood effects in word recognition. Psychonomic Bulletin and Review, 8 , $531-544$.

Coltheart, M. (1980a). Deep dyslexia: A review of the syndrome. In M. Coltheart, K. Patterson and J.C. Marshall (Eds.), Deep Dyslexia. London: Routledge \& Kegan Paul. Coltheart, M. (1980b). Deep dyslexia: A right-hemisphere hypothesis. In M. Coltheart, K. Patterson and J.C. Marshall (Eds.), Deep Dyslexia. London: Routledge \& Kegan Paul.

Coltheart, M. (2000). Deep dyslexia is right-hemisphere reading. Brain and Language, 71, 299-309.

Craik, R.I.M. \& Lockhart, R.S. (1972). Levels of processing: A framework for memory research. Journal of Verbal Learning and Verbal Behavior, 11, 671-684.

Damian, M.F., Vigliocco, G., \& Levelt, W.J.M. (2001). Effects of semantic context in the naming of pictures and words. Cognition, 81, B77-B86.

Friedman, R.B. (1996). Recovery from deep alexia to phonological alexia: Points on a continuum. Brain and Language, 52, 114-128.

Glosser, G. \& Friedman, R.B. (1990). The continuum of deep/phonological dyslexia. Cortex, 26, 343-359. 
Hildebrandt, N., \& Sokol, S.M. (1993). Implicit sublexical phonological processing in an acquired deep dyslexic patient. Reading and Writing, 5, 43-68.

Jarvis, B. (2002). Direct RT Reaction Time Software (v2002). www.empirisoft.com,

Katz, R.B., \& Lanzoni, S.M. (1992). Automatic activation of word phonology from print in deep dyslexia. Quarterly Journal of Experimental Psychology, 45 A, 575608.

Katz, R.B., \& Lanzoni, S.M. (1997). Activation of the phonological lexicon for reading and object naming in deep dyslexia. Brain \& Language, 58, 46-60.

Hinton, G.E. \& Shallice, T. (1991). Lesioning an attractor network: Investigations of acquired dyslexia. Psychological Review, 98, 74-95.

Klein, D., Behrmann, M., \& Doctor, E. (1994). The Evolution of deep dyslexia: Evidence for the spontaneous recovery of the semantic reading route. Cognitive Neuropsychology, 11, 579-611.

Klein, R., Briand, K., Smith, L., \& Smith-Lamothe, J. (1988). Does spreading activation summate? Psychological Research, 50, 50-54.

Lockhart, R.S. \& Craik, F.I. (1990). Levels of processing: A retrospective commentary on a framework for memory research. Canadian Journal of Psychology, 44, $87-112$.

Marshall, J.C. \& Newcombe, F. (1973). Patterns of paralexia: A psycholinguistic approach. Journal of Psycholinguistic Research, 2, 1975-1999.

Mather, M., Henkel, L.A., \& Johnson, M.K. (1997). Evaluating characteristics of false memories: Remember/know judgements and memory characteristics questionnaire compared, Memory and Cognition, 25, 826-837. 
McEwen, S., Westbury, C., Buchanan, L., \& Libben, G. (2001). Semantic information is used by a deep dyslexic to parse compound. Brain and Cognition, 46, 201205.

McKoon, G. \& Ratcliff, R. (1992). Spreading activation versus compound cue accounts of priming: Mediated priming revisited. Journal of Experimental Psychology: Learning, Memory, and Cognition, 18, 1155-1172.

McNamara, T.P. (1992a). Priming and constraints it places on theories of memory and retrieval. Psychological Review, 99, 650-662.

McNamara, T.P. (1992b). Theories of priming: 1. Associative distance and lag. Journal of Experimental Psychology: Learning, Memory, and Cognition, 18, 1173-1190.

McNamara, T.P. (1994). Theories of priming: II. Types of primes. Journal of Experimental Psychology: Learning, Memory, and Cognition, 20, 507-520.

Meyer, D.E., \& Schvaneveldt, R.W. (1971). Facilitation in recognizing pairs of words: Evidence of a dependence between retrieval operations. Journal of Experimental Psychology, 90, 227-234.

Morton, J. \& Patterson, K.E. (1980). A new attempt at an interpretation, or, an attempt at a new interpretation. In M. Coltheart, K. Patterson and J.C. Marshall (Eds.), Deep Dyslexia. London: Routledge \& Kegan Paul.

Plaut, D. C. (1999). Computation modeling of word reading, acquired dyslexia, and remediation. In R. Klein, \& P. McMullen (Eds). Converging methods for understanding reading and dyslexia. Cambridge, MA, US: The Mit Press.

Plaut, D. \& Shallice T. (1993). Deep Dyslexia: A case study of a connectionist neuropsychology. Cognitive Neuropsychology, 10, 377-500. 
Reisburg, D. (1997).Language. Cognition: Exploring the Science of the Mind. W.W. Norton \& Company, Inc., New York, N.Y.

Rips, L., Shoben, E.J., \& Smith, E.E. (1973). Semantic distance and the verification of semantic relations. Journal of Verbal Learning and Verbal Behaviour, 12 , $1-20$.

Sartori, G., Barry, C., \& Job, R. Phonological dyslexia: A review. In R.N. Malatesha and H.A. Whitaker (eds.), Dyslexia: A Global Issue. The Hague: Martinus Nijhoff, 1984, pp. 339-356.

Schmidt, R. (1976). On the spread of semantic excitation. Psychological Research, 38, 333-353.

Southwood, M.H. \& Chatterjee, A. (2001). The simultaneous activation hypothesis: Explaining recovery from deep to phonological dyslexia. Brain and Language, $76,18-34$.

Toglia, M.P., Neuschatz, J.S., \& Goodwin, K.A. (1999). Recall accuracy and illusory memories: When more is less. Memory, $7,233-256$.

Wilshire, C.E. \& McCarthy, R.A. (2002). Evidence for a context-sensitive word retrieval disorder in a case of nonfluent aphasia. Cognitive Neuropsychology, 19, 165186. 
APPENDIX 1. Items from the LD and Naming Tasks

\begin{tabular}{|l|l|l|l|l|}
\hline List 1 & List 3 & List 5 & List 7 & List 9 \\
butter & table & hot & shoe & queen \\
food & sit & snow & hand & england \\
eat & legs & warm & toe & crown \\
sandwich & seat & winter & kick & prince \\
rye & couch & ice & sandals & george \\
jam & desk & wet & soccer & dictator \\
milk & recliner & frigid & yard & palace \\
flour & sofa & chilly & walk & throne \\
jelly & wood & heat & ankle & arm \\
dough & cushion & weather & rule \\
crust & swivel & freeze & boot & subjects \\
slice & stool & air & monarch \\
wine & sitting & shiver & royal \\
loaf & rocking & arctic & sock \\
toast & bench & knee & leader \\
frost & reign \\
\hline
\end{tabular}

\begin{tabular}{|c|c|c|c|c|}
\hline $\begin{array}{l}\text { List } 2 \\
\text { truck } \\
\text { bus } \\
\text { train } \\
\text { automobile } \\
\text { vehicle } \\
\text { drive } \\
\text { jeep } \\
\text { ford } \\
\text { race } \\
\text { keys } \\
\text { garage } \\
\text { highway } \\
\text { sedan } \\
\text { van } \\
\text { taxi }\end{array}$ & $\begin{array}{l}\text { List } 4 \\
\text { town } \\
\text { crowded } \\
\text { state } \\
\text { capital } \\
\text { streets } \\
\text { subway } \\
\text { country } \\
\text { new york } \\
\text { village } \\
\text { metropolis } \\
\text { big } \\
\text { chicago } \\
\text { suburb } \\
\text { county } \\
\text { urban }\end{array}$ & $\begin{array}{l}\text { List } 6 \\
\text { nurse } \\
\text { sick } \\
\text { lawyer } \\
\text { medicine } \\
\text { health } \\
\text { hospital } \\
\text { dentist } \\
\text { physician } \\
\text { ill } \\
\text { patient } \\
\text { office } \\
\text { stethoscope } \\
\text { surgeon } \\
\text { clinic } \\
\text { cure }\end{array}$ & \begin{tabular}{|l} 
List 8 \\
apple \\
vegetable \\
orange \\
kiwi \\
citrus \\
ripe \\
pear \\
banana \\
berry \\
cherry \\
basket \\
juice \\
salad \\
bowl \\
cocktail
\end{tabular} & $\begin{array}{l}\text { List } 10 \\
\text { note } \\
\text { sound } \\
\text { piano } \\
\text { sing } \\
\text { radio } \\
\text { band } \\
\text { melody } \\
\text { horn } \\
\text { concert } \\
\text { instrument } \\
\text { symphony } \\
\text { jazz } \\
\text { orchestra } \\
\text { art } \\
\text { rhythm }\end{array}$ \\
\hline
\end{tabular}




\begin{tabular}{|l|l|l|l|l|}
\hline List 11 & List 13 & List 15 & List 17 & List 19 \\
thread & bed & nose & hard & sour \\
pin & rest & breathe & light & candy \\
eye & awake & sniff & pillow & sugar \\
sewing & tired & aroma & plush & bitter \\
sharp & dream & loar & good \\
point & wake & see & cotton & taste \\
prick & snooze & nostril & fur & tooth \\
thimble & blanket & whiff & tough & nice \\
haystack & doze & scent & fluffy & honey \\
thorn & slumber & reek & feather \\
hurt & snore & stench & fodarry \\
injection & nap & fragrance & downy & chocolate \\
syringe & peace & perfume & kitten \\
cloth & yawn & salts & cake \\
knitting & drowsy & rose & tart \\
pie
\end{tabular}

\begin{tabular}{|l|l|l|l|l|}
\hline List 12 & List 14 & List 16 & List 18 & List 20 \\
blouse & fast & cigarette & web & door \\
sleeves & lethargic & puff & insect & glass \\
pants & stop & blaze & bug & pane \\
tie & listless & billows & fright & shade \\
button & snail & pollution & fly & ledge \\
shorts & cautious & ashes & arachnid & sill \\
iron & delay & cigar & crawl & house \\
polo & traffic & chimney & tarantula & open \\
collar & turtle & fire & poison & curtain \\
vest & hesitant & tobacco & bite & frame \\
pocket & speed & stink & creepy \\
jersey & quick & pipe & animal \\
belt & sluggish & lungs & ugly \\
linen & wait & flames & sash \\
cuffs & feelers & screen \\
molasses & stain & small & \\
\hline
\end{tabular}




\section{VITA AUCTORIS}

NAME: $\quad$ Annette Colangelo

PLACE OF BIRTH: Edmonton, Alberta

YEAR OF BIRTH: 1973

EDUCATION: $\quad$ St. Mary's High School, Alberta 1988-1991

University of Alberta, Edmonton, Alberta 1995-2000 B.A. with distinction

University of Windsor, Windsor, Ontario 2001-2003, M.A. 